

1,2 Departamento de Medicina y Zootecnia de Aves, Facultad de Medicina Veterinaria y Zootecnia, Universidad Nacional Autónoma de México. CDMX. 04510.

${ }^{3}$ Universidad Autónoma del Estado de Hidalgo. Tulancingo, Hidalgo. 43600.

* Autor para correspondencia: Correo electrónico: nlca@unam.mx
Recibido: 2018-09-26 Aceptado: 2019-04-03 Publicado: 2019-06-11 Información y declaraciones adicionales en la página 15

(c) Derechos de autor: Norma L. Calderón Apodaca et al. 2019

acceso abierto $\mathbf{0}$

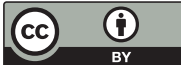

\section{Hallazgos clínico patológicos de la enfermedad de Marek en aves de combate}

\section{Resumen}

Descripción de los casos. Se analizaron siete casos clínicos de doce aves de combate de diferentes edades, estos casos fueron documentados entre 2015 y 2016. El diagnóstico presuntivo fue enfermedad de Marek, porque expresaron signos de esta enfermedad.

Hallazgos clínicos e interpretación. Los signos clínicos fueron principalmente respiratorios, circulatorios y nerviosos. La observación histopatológica reveló cambios celulares importantes con infiltrado linfoide en diferentes tejidos, mayoritariamente en pulmón, hígado, encéfalo, nervios, intestino, riñón y bazo, con lo que se diagnosticó enfermedad de Marek.

Tratamiento y evolución. Se desconoce si se aplicó tratamiento.

Pruebas de laboratorio. En el estudio histopatológico, los cortes se incluyeron en formol al $10 \%$ con tinciones de rutina. Las muestras analizadas fueron tejido perineural, encéfalo, nervio ciático braquial, pulmón, corazón, hígado, duodeno, páncreas, riñón, bazo, ciegos, bolsa de Fabricio y piel de los senos infraorbitarios. Se determinó la severidad y virulencia del virus infectante según el criterio de infiltrado linfocitario definido en las pruebas de laboratorio.

Relevancia clínica. Debido a que la crianza de aves de combate se realiza en pequeña y mediana escala, y bajo métodos tradicionales, el virus de la enfermedad de Marek persiste en estas aves. Por lo tanto, se requiere

\section{Una forma de citar este artículo:}

Calderón-Apodaca NL, Araujo-Mayorga MI, Zepeda-Velázquez AP. Hallazgos clínico patológicos de la enfermedad de Marek en aves de combate. Clínica Veterinaria: abordaje diagnóstico y terapéutico. 2019;5:e33201955. doi:10.22201/fmvz.23958766e.201933. 
el diseño y la implementación de programas especiales de vacunación, incluyendo la producción de vacunas en una presentación adecuada para pequeños avicultores.

Palabras clave: aves de combate, Marek, tumor, vacunación.

\section{Clinical and pathological findings of Marek's disease in fighting cocks}

\section{Abstract}

Cases report. Seven clinical cases of twelve fighting cocks of different ages, were analyzed, this cases were documented between 2015 and 2016. The presuntive diagnosis was Marek's disease, because they expressed signs of this disease.

Clinical findings. The clinical signs were mainly respiratory, circulatory and nervous. Histopathological observation revealed major cell changes with lymphoid infiltrates in different tissues, mostly in the lung, liver, brain, nerves, bowel, kidney, and spleen, leading to the diagnosis of Marek's disease.

Treatment and evolution. Whether treatment was applied is unknown.

Laboratory tests. In the histopathological study, the cuts were included in $10 \%$ formaldehyde with routine stains. The samples analyzed were perineural tissue, brain, sciatic brachial nerve, lung, heart, liver, duodenum, pancreas, kidney, spleen, blind, bursa of Fabricius and skin of infraorbital sinuses. The severity and virulence of the infecting virus was determined according to the lymphocyte infiltrate criterion defined in the laboratory tests. Clinical relevance. Because the breeding of fighting cocks is realized in small to medium scale and under traditional methods, the Marek's disease virus persists in these birds. Therefore the design and implementation of special vaccination programs are required, including the production of vaccines in a presentation suitable for small flocks.

Keywords: fighting cocks, Marek's disease, tumor, vaccination. 


\section{Descripción de los casos}

Analizamos siete casos clínicos de doce aves de combate de diferentes edades, documentadas entre 2015 y 2016, y que fueron remitidas al Departamento de Medicina y Zootecnia de Aves de la Facultad de Medicina Veterinaria y Zootecnia de la UNAM (DMZA de la FMVZ, UNAM). Seleccionamos los casos según el diagnóstico presuntivo de enfermedad de Marek (EM) por semiología. En estas aves encontramos tumores que consideramos un factor independiente a la selección de los casos.

El sistema de producción era principalmente de traspatio, con diferentes prácticas de alojamiento, en las que predominaba el piso de tierra. La alimentación consistía en alimento balanceado para gallos, complementado con verduras y frutas. La población multiedad variaba entre 40 y hasta 380 ejemplares. Las medidas de prevención consistían en la aplicación de vacunas, en seis de los siete casos clínicos, se aplicó la vacuna contra la enfermedad de Newcastle (ENC); a cuatro se les había aplicado la triple aviar (VTA); cuatro aves estaban vacunadas contra viruela aviar (VA); solo a una se le vacunó para bronquitis infecciosa (BI) y únicamente dos de los propietarios vacunaron a las aves contra la enfermedad de Marek (VEM).

\section{Hallazgos clínicos e interpretación}

Los signos clínicos fueron secreción, mucosa nasal, disnea, estertores traqueales, depresión, inflamación del ojo, crestas y barbillas pálidas, zonas aptéricas en el cuello, arritmia cardiaca, tortícolis, epistótonos y opistótonos; ataxia, parálisis de los miembros pélvicos y caída de las alas.

Durante la inspección ante mortem, se observaron principalmente signos nerviosos, en la región pericloacal y excremento y uratos adheridos a las plumas, entre otros (Cuadro 1). Todos los hallazgos se ven en el Cuadro 2, donde se observa que el más afectado es el sistema digestivo: la ingluvia dilatada y petequias en la mucosa del proventrículo. En el duodeno, se encontró un nódulo de aproximadamente tres milímetros de diámetro, firme al tacto y de color amarillo. La mucosa del intestino estaba engrosada y de color naranja, con congestión difusa moderada y zonas hemorrágicas (5 \% de la mucosa). Los sacos ciegos estaban distendidos por abundante gas.

En el intestino delgado y el ciego, se detectaron abundantes parásitos cilíndricos blancos de uno a tres centímetros de largo, que morfológicamente son compatibles con el género Ascaridia spp. El hígado con hepatomegalia, pálido, esteatósico y congestionado con zonas blancas irregulares distribuidas de manera difusa de aproximadamente un milímetro de diámetro y nódulos blancos de unos tres milímetros de diámetro que profundizan en el corte.

En la luz de la tráquea había exudado mucoso amarillo; en los pulmones, zonas irregulares grises y amarillas (30\% del parénquima), áreas multifocales grises (66 \% del órgano), zonas de color rojo oscuro y de consistencia firme (80 \% del parénquima), y sacos aéreos abdominales engrosados y opacos. Se apreció una marcada depresión en el ventrículo derecho, cerca de la región coronaria; engrosamiento y opacidad del saco pericárdico con hidropericardio (líquido transparente). En los tejidos linfoides, se observó esplenomegalia y puntos blancos 
Cuadrol. Hallazgos ante mortem y signos clínicos de los casos remitidos

\begin{tabular}{|c|c|c|}
\hline Caso & N & Inspección externa \\
\hline \multirow{2}{*}{1} & $\begin{array}{c}1 \\
7 \text { meses }\end{array}$ & $\begin{array}{l}\text { Seno infraorbitario derecho: aumentado de tamaño en grado moderado. Ausencia del globo } \\
\text { ocular derecho y líquido traslúcido con estrías de sangre. }\end{array}$ \\
\hline & $\begin{array}{c}2 \\
36 \text { meses }\end{array}$ & Epistótono, parálisis bilateral de los miembros posteriores y parálisis unilateral del ala derecha. \\
\hline \multirow{3}{*}{2} & 7 meses & $\begin{array}{l}\text { Miembro posterior izquierdo con parálisis severa. Región pericloacal con heces y uratos (RPS). } \\
\text { CC1. }\end{array}$ \\
\hline & 5 meses & $\begin{array}{l}\text { Ojo derecho cerrado. Región lumbosacra aptérica. Miembro posterior derecho con parálisis } \\
\text { severa. RPS. CC1. }\end{array}$ \\
\hline & 3 y 4 & Disnea y abundante cantidad de ectoparásitos. \\
\hline $3^{*}$ & $\begin{array}{c}5 \\
72 \text { meses }\end{array}$ & Zonas aptéricas de la cara y las barbillas con descamación severa. RPS. \\
\hline 4 & $\begin{array}{c}6 \\
10 \text { meses }\end{array}$ & Cianosis en la punta de la cresta. RPS. CC2. \\
\hline $5 *$ & $\begin{array}{c}7 \\
28 \text { meses }\end{array}$ & Piel de la cara color rosa claro. CC3. \\
\hline 6 & $\begin{array}{c}8 \text { y } 9 \\
6 \text { meses }\end{array}$ & $\mathrm{CCl}$ \\
\hline \multirow[b]{2}{*}{7} & $\begin{array}{l}10 \text { y } 11 \\
18 \text { meses }\end{array}$ & CC3 \\
\hline & $\begin{array}{c}12 \\
2 \text { meses }\end{array}$ & CC2 \\
\hline
\end{tabular}

*Las aves se recibieron muertas, al resto de las aves se les aplicó eutanasia por el método de dislocación cervical.

CC1. Condición corporal 1: caquexia.

CC2. Condición corporal 2: huesos prominentes y desarrollo de músculos pectorales moderado.

CC3. Condición corporal 3: desarrollo de musculatura normal.

Cuadro 2. Historia clínica y hallazgos macroscópicos identificados en los casos clínicos estudiados

\begin{tabular}{|c|c|c|c|c|c|}
\hline Caso & No. Ave & Vacunación & Signos clínicos & Cuadro nervioso & Hallazgos macroscópicos relevantes \\
\hline 1 & 1 & $\begin{array}{l}\text { ENC VA } \\
\text { FNCV/A }\end{array}$ & D R & + & I Nervios ciáticos engrosados, grado moderado \\
\hline \multirow[b]{2}{*}{2} & 3 & ENC & \multirow[b]{2}{*}{ D R C } & + & \multirow{2}{*}{$\begin{array}{l}\text { I Plexo lumbosacro y nervios ciáticos engrosados y } \\
\text { con pérdida de las estriaciones } \\
\text { I Pulmones con zonas irregulares de color gris y } \\
\text { amarillo }\end{array}$} \\
\hline & 4 & ENC & & + & \\
\hline 3 & 5 & $\begin{array}{l}\text { ENC } \\
\text { VA }\end{array}$ & $\mathrm{DCU}$ & + & $\begin{array}{l}\text { I Nervios braquiales y ciáticos aumentados de } \\
\text { tamaño, grado severo }\end{array}$ \\
\hline 4 & 6 & $\begin{array}{l}\text { ENC VTA } \\
\text { VA }\end{array}$ & LDC & + & $\begin{array}{l}\text { I Plexo braquial y nervios ciáticos con } \\
\text { engrosamiento leve }\end{array}$ \\
\hline 5 & 7 & $\begin{array}{l}\text { ENC } \\
\text { VTA }\end{array}$ & LDRCUM & + & $\begin{array}{l}\text { I Esplenomegalia con puntos blancos multifocales } \\
\text { de } 1 \mathrm{~mm} \text { de diámetro } \\
\text { I Engrosamiento del nervio ciático derecho, grado } \\
\text { leve y pérdida de estriaciones }\end{array}$ \\
\hline \multirow[b]{2}{*}{6} & 8 & ENC VTA VA & \multirow[b]{2}{*}{ LDRC } & + & \multirow{2}{*}{$\begin{array}{l}\text { I Zonas irregulares difusas de color blanco en } \\
\text { hígado y presencia de nódulos blancos } \\
\text { I Plexo lumbosacro y plexo braquial engrosados, } \\
\text { grado severo }\end{array}$} \\
\hline & 9 & $\begin{array}{l}\text { ENC TA } \\
\text { VA }\end{array}$ & & + & \\
\hline \multirow{3}{*}{7} & 10 & $\begin{array}{l}\text { VTA BI } \\
\text { VEM }\end{array}$ & \multirow{3}{*}{ SD } & \multirow{3}{*}{ SD } & \multirow{3}{*}{ SD } \\
\hline & 11 & $\begin{array}{l}\text { VTA BI } \\
\text { VEM }\end{array}$ & & & \\
\hline & 12 & $\begin{array}{l}\text { VTA BI } \\
\text { VEM }\end{array}$ & & & \\
\hline
\end{tabular}

ENC = Vacuna contra la enfermedad de Newcastle, VTA= vacuna triple aviar (antígeno contra la enfermedad de Newcastle,

Pausteurella multocida tipo A y Pausteurella multocida tipo x73), VA= vacuna contra viruela aviar, $\mathrm{Bl}=$ vacuna contra bronquitis infecciosa, VEM= vacuna contra enfermedad de Marek.

$+=$ signos clínicos nerviosos, $\mathrm{D}=$ digestivos, $\mathrm{R}=$ respiratorios, $\mathrm{C}=$ circulatorio, $\mathrm{U}=$ urinario, $\mathrm{L}=$ linfoide, $\mathrm{M}=$ muscular, $\mathrm{SD}=\sin$ datos. 
multifocales de un milímetro de diámetro; además la bolsa de Fabricio estaba dilataday atrofiada de las folias.

Tenían nefromegalia y palidez renal con múltiples petequias en el corte. La clasificación del infiltrado linfocitario basado en la severidad, identificado en los tejidos provenientes de los siete casos analizados, se muestra en el Cuadro 3; donde se ve cómo en la histopatología, las 12 aves tenían infiltrados linfocitarios pleomórficos caracterizados por la variación en el tamaño de las células, hipercromatismo y maduración celular, y núcleos irregulares, independientemente de las lesiones tumorales. En la piel de la región del seno infraorbitario: dermatitis, paniculitis linfocitaria multifocal moderada y edema difuso moderado.

En el examen histopatológico, los nervios estaban engrosados, había pérdida de las estriaciones y coloración amarilla leve, moderada y severa (Figuras 1 y 2); así como degeneración Walleriana de las fibras nerviosas, focos de degeneración y desmielinización severa con infiltrado de linfocitos localizados e infiltrado de manera multifocal, difusa e intersticial, tanto en el parénquima como en las meninges, y perivascular en grado moderado a severo (Figuras 3 y 4 ). Además de edema e infiltrados de linfocitos pleomórficos, de manera intersticial, perivascular y nodular, en distribución zonal y difusa, de moderada a severa (Figuras 5-7).

En el tejido perineural de solo uno de los casos, se observó infiltrado linfocitario difuso severo (Figura 8); con neumonía intersticial multifocal moderada caracterizada por infiltrado leucocitario; en algunas de las aves proliferaron las células linfoides pleomórficas en forma nodular, intersticial, perivascular y difusa en grado severo (Figura 9).

En el corazón y el hígado, proliferaron células linfoides pleomórficas en forma nodular, intersticial y perivascular con distribución multifocal colalescente y difusa en grado moderado (Figura 10). En el duodeno y yeyuno, se encontró una enteritis linfocitaria pleomórfica multifocal coalescente y difusa de moderada a severa, con abundante exudado necrótico e inflamatorio entre las vellosidades y numerosos parásitos compatibles con coccidias.

En la mucosa de los ciegos se observó infiltrado difuso moderado de células linfocitarias. En el páncreas abundaba en infiltrado linfoide multifocal coalescente de moderado a severo de células linfocitarias en diferentes estadios de maduración y con abundantes figuras mitóticas y hemorragias multifocales. Bazo con depleción linfocitaria y grupos de linfocitos pleomórficos con distribución difusa severa; necrosis de vasos sanguíneos, focos de hemorragia e hiperplasia linfoide moderada.

En el riñón proliferaron las células linfoides pleomórficas nodulares y multifocales coalescentes intersticiales, perivasculares y difusas en grado severo, con degeneración, grasa multifocal leve y hemorragias multifocales. La bolsa de Fabricio tenía infiltrado intersticial difuso de células linfocitarias en diferentes etapas de maduración con abundantes figuras mitóticas (Figuras 11 y 12), atrofia general del órgano y numerosos granulomas con centro necrótico.

\section{Tratamiento y evolución}

Las aves presentaron diferentes condiciones corporales, entre las que se identificó emaciación y anorexia. Se desconoce si se aplicó tratamiento. 
Cuadro 3. Hallazgos histopatológicos

\begin{tabular}{|c|c|c|c|c|c|c|c|c|c|c|c|c|}
\hline Ave & Encéfalo & $\begin{array}{l}\text { Nervio } \\
\text { clático }\end{array}$ & $\begin{array}{l}\text { Nervio } \\
\text { braquial }\end{array}$ & Pulmón & Corazón & Migado & $\begin{array}{l}\text { Duodeno/ } \\
\text { páncreas }\end{array}$ & Ritión & Baro & $\begin{array}{l}\text { Ciegos/ } \\
\text { intestino }\end{array}$ & $\begin{array}{l}\text { Bolsa de } \\
\text { Fabricio }\end{array}$ & Piel \\
\hline 1 & - & - & - & ++ & - & - & $-/-$ & - & - & $++/-$ & - & ++ \\
\hline 2 & +++ & - & - & - & - & - & ++- & - & - & - & - & - \\
\hline 3 & + & +++ & +++ & - & - & - & - & - & - & - & - & - \\
\hline 4 & + & + & + & + & + & + & - & + & - & - & - & - \\
\hline 5 & ++ & - & - & ++ & - & ++ & - & - & ++ & - & - & - \\
\hline 6 & +++ & ++ & ++ & - & +++ & +++ & $-/+++$ & +++ & - & $-/+++$ & - & - \\
\hline 7 & - & + & + & ++ & ++ & +++ & $++/++$ & +++ & +++ & - & - & - \\
\hline 8 & ++ & ++ & ++ & ++ & - & ++ & - & - & - & $-/++$ & ++ & - \\
\hline 9 & ++ & ++ & ++ & ++ & - & ++ & - & - & - & $-/++$ & ++ & - \\
\hline 10 & ++ & + & + & - & - & ++ & - & ++ & - & ++ & - & - \\
\hline 11 & ++ & + & + & - & - & ++ & - & ++ & - & $-/+$ & - & - \\
\hline 12 & ++ & + & + & - & - & ++ & - & ++ & - & $-/++$ & - & - \\
\hline
\end{tabular}

(-) Sin cambios patológicos aparentes.

(+) Infiltrado linfocitario leve y disperso, o erivascular, así como lesiones vasculares.

$(++)$ Infiltrado linfocitario moderado perivascular y multifocal.

(+++) Infiltrado linfocitario severo, multifocal o coalescente, conformado en diferentes capas con pérdida de la arquitectura celular. 


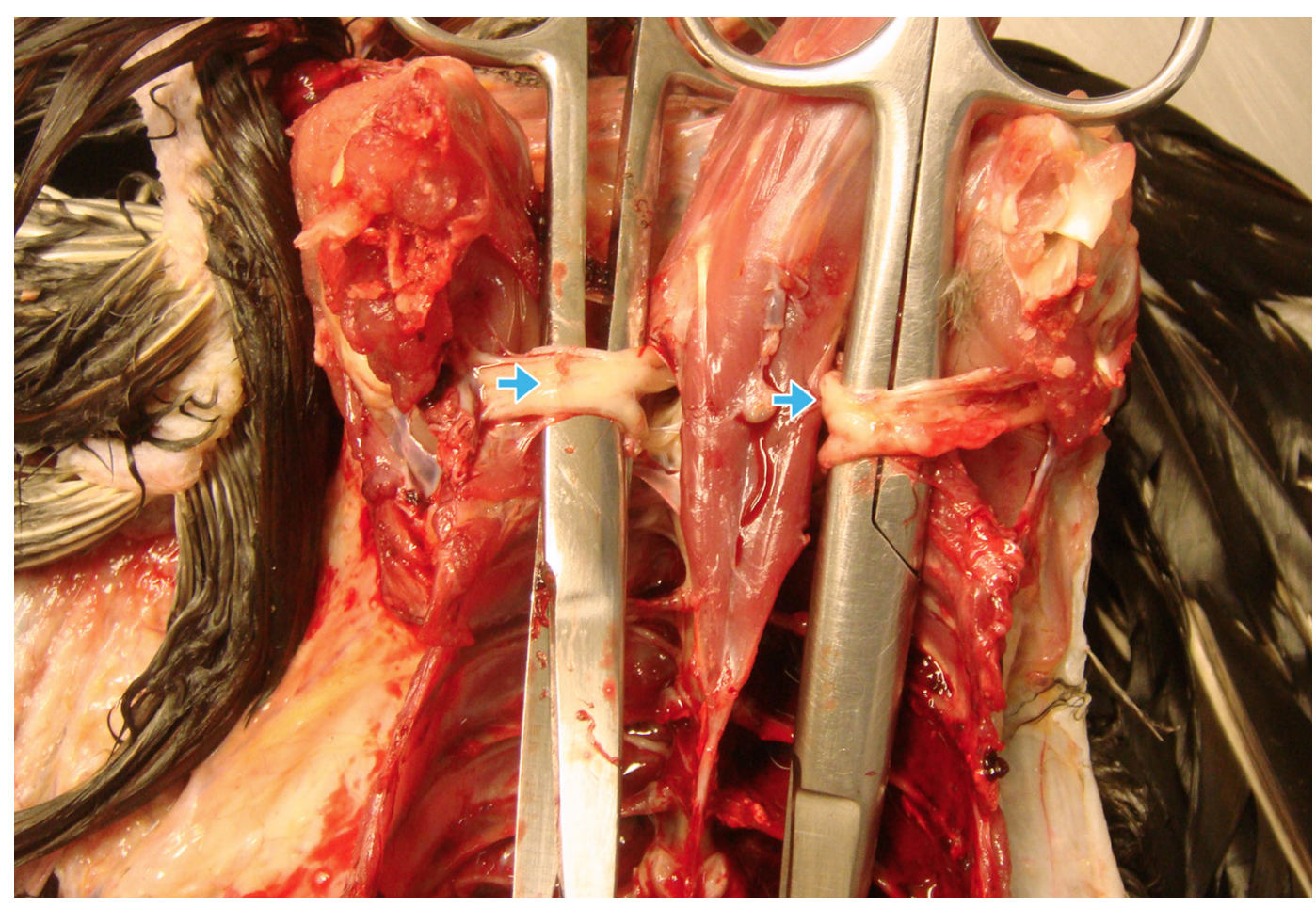

Figura 1. Ave de combate. Nervios braquiales aumentados de tamaño (flechas).

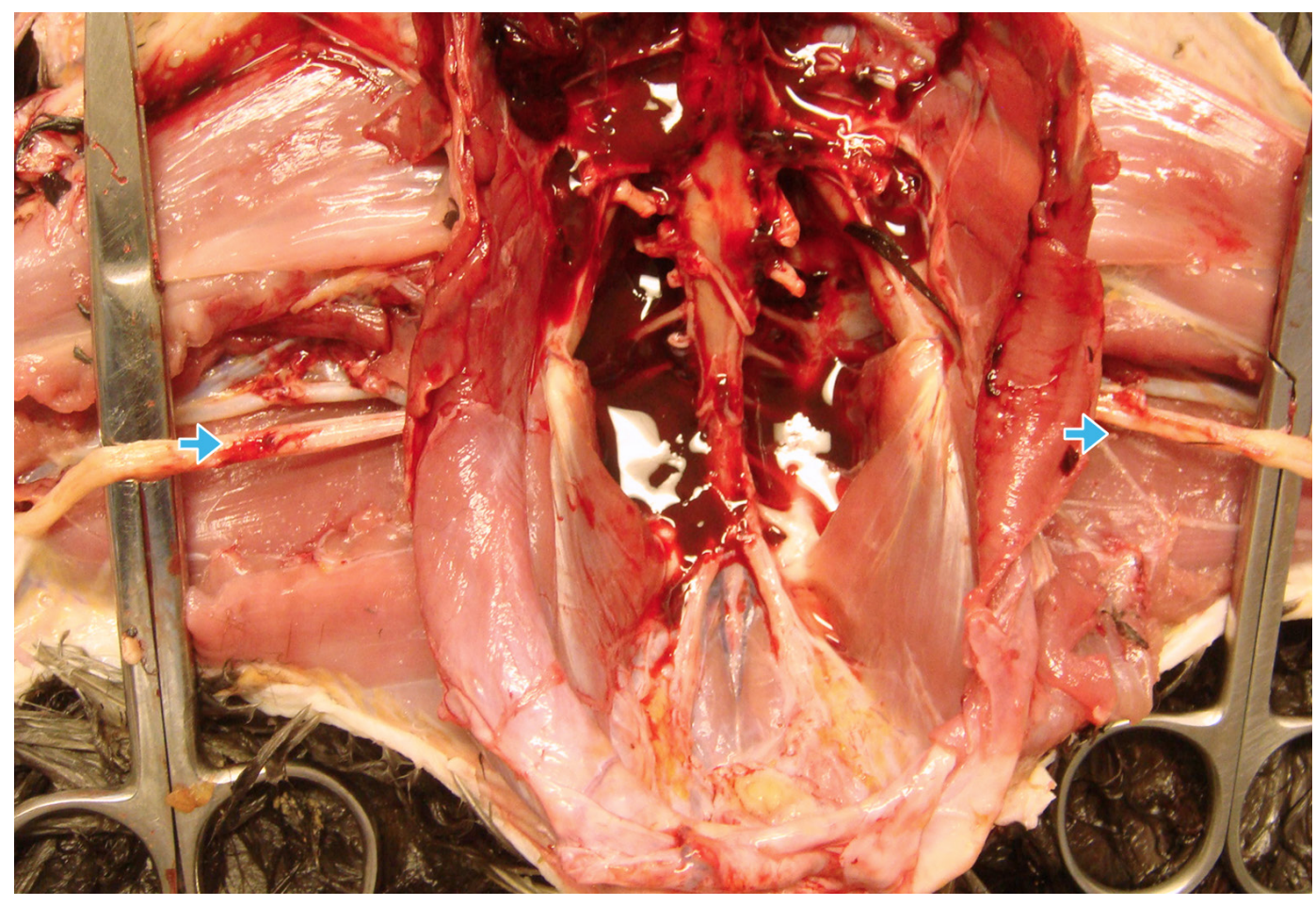

Figura 2. Ave de Combate. Nervios ciáticos aumentados de tamaño y de coloración amarillenta (flechas). 


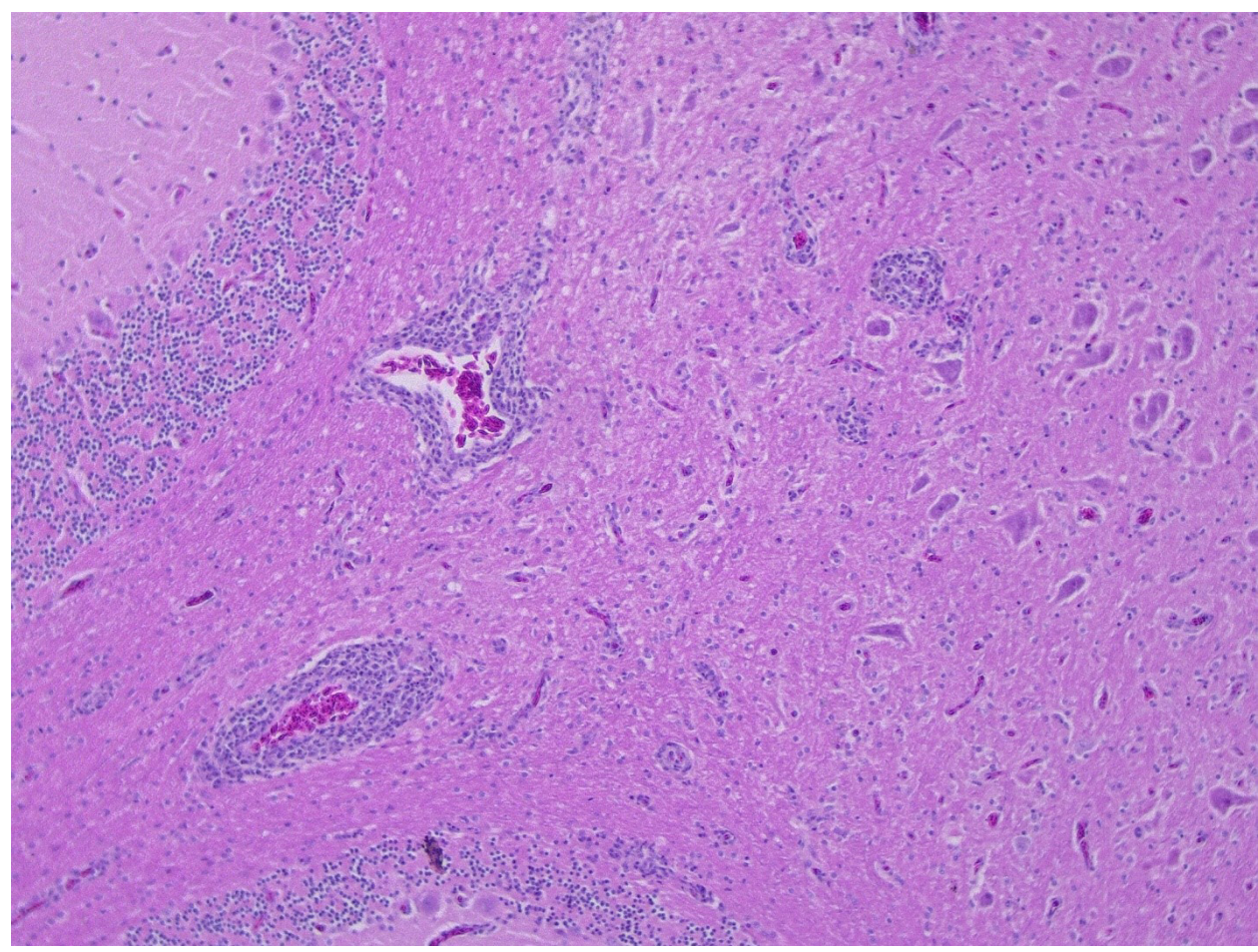

Figura 3. Encéfalo. Infiltrado linfocitario neoplásico perivascular.



Figura 4. Encéfalo. Infiltrado perivascular con células linfoides pleomórficas. 


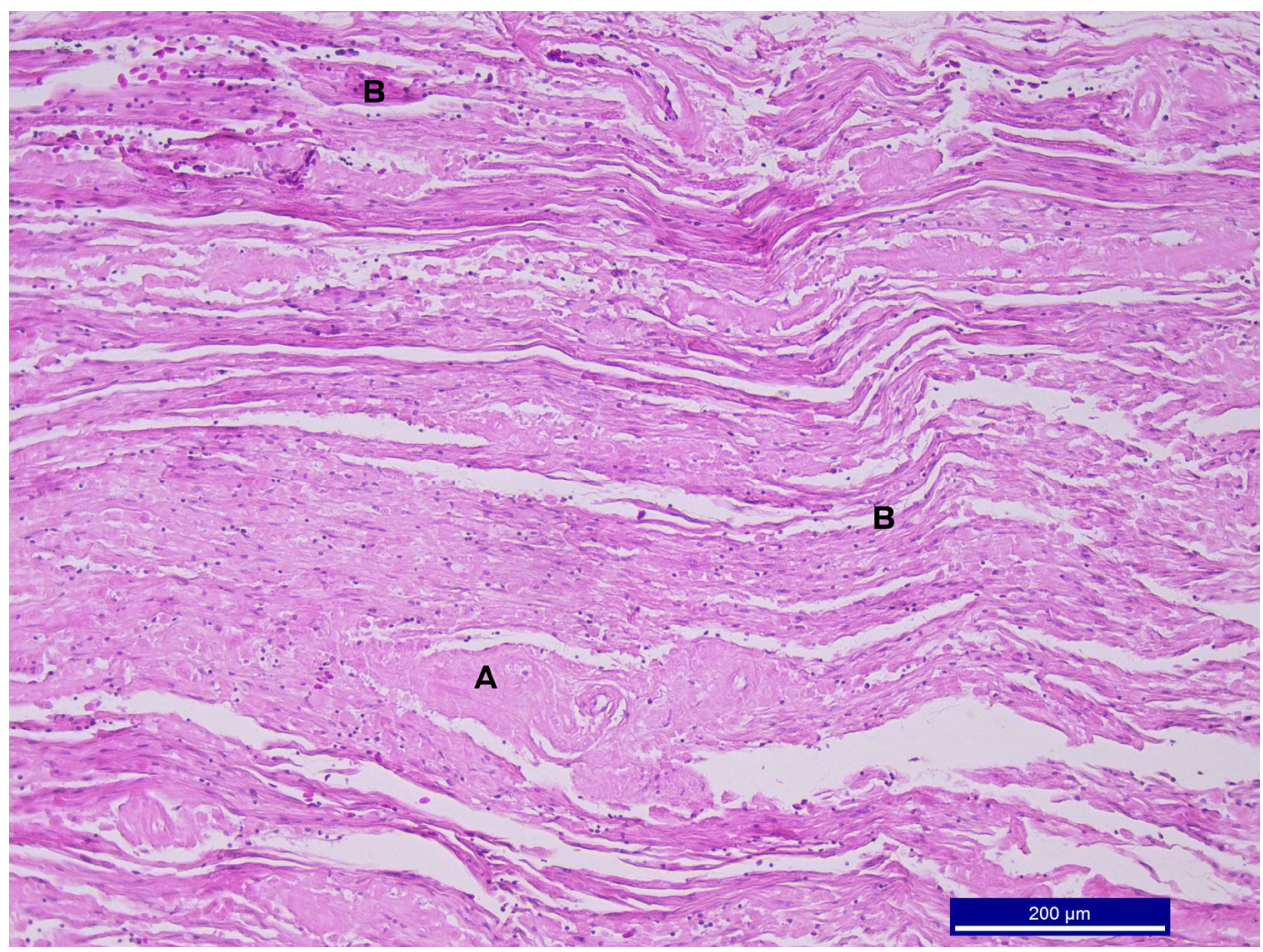

Figura 5. Nervio. Desmielinización severa con infiltrado linfocitario difuso:

A) zona de desmielinización, B) infiltrado linfocitario.

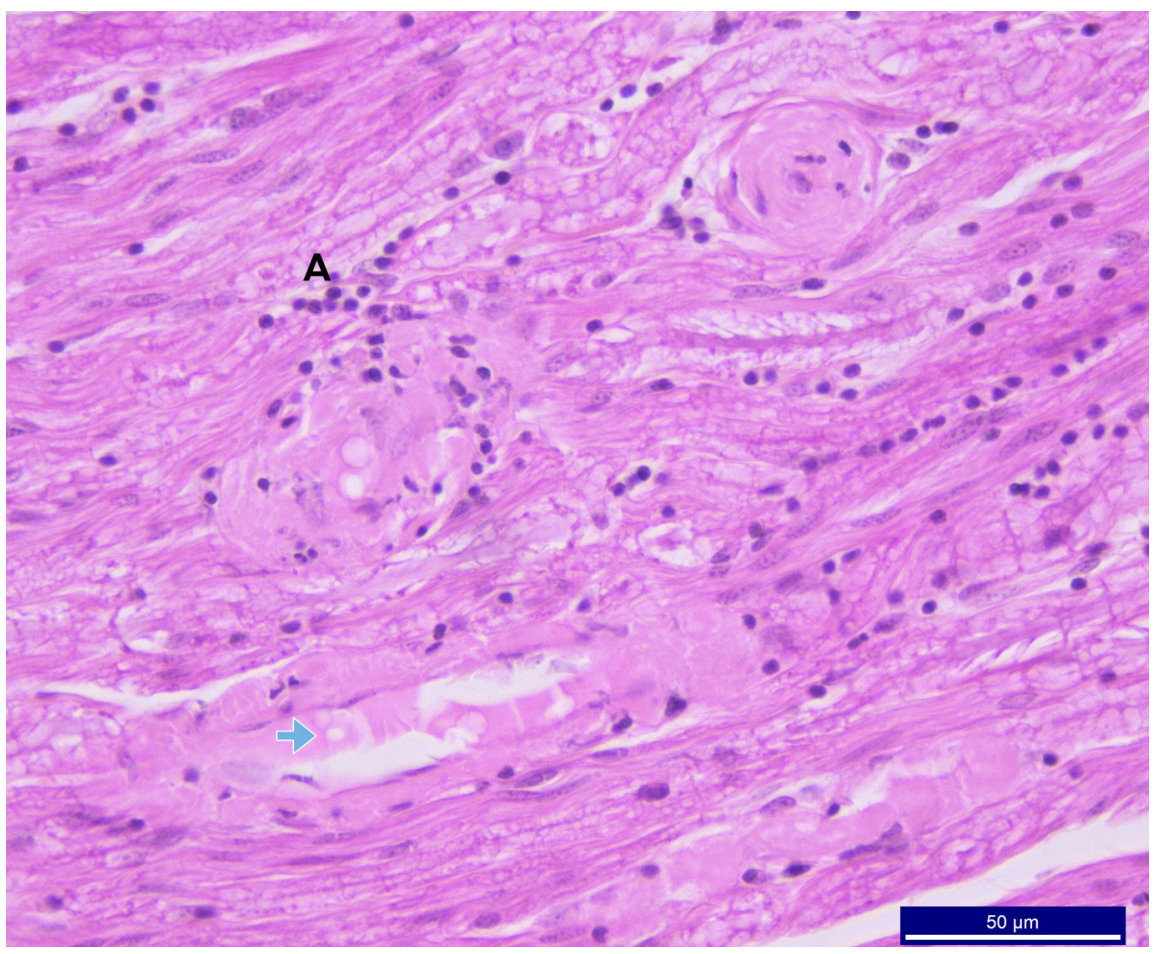

Figura 6. Nervio. Desmielinización (flecha) e infiltrado focal leve de linfocitos (A). 


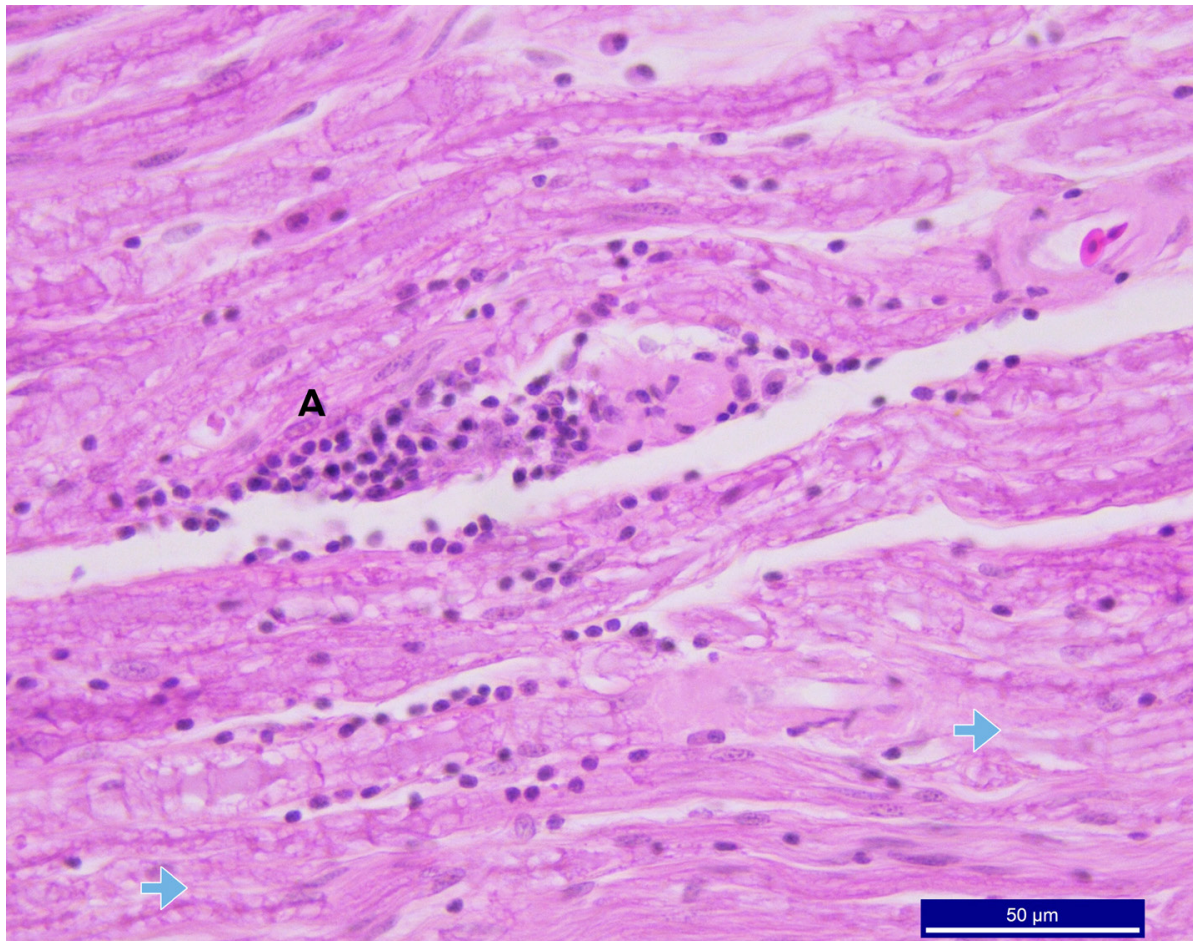

Figura 7. Nervio. Degeneración (flechas) e infiltrado focal moderado de linfocitos (A).

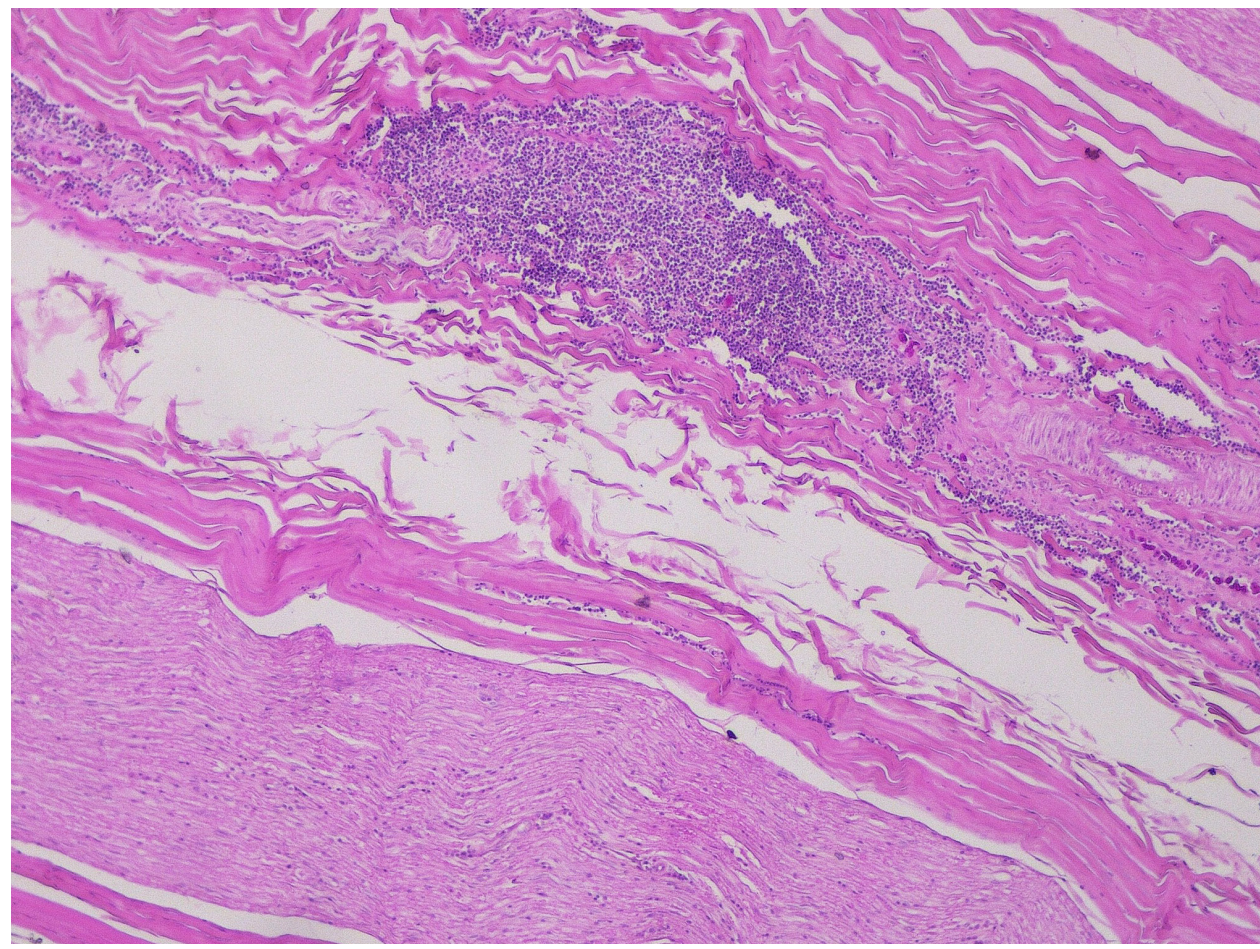

Figura 8. Nervio. Infiltrado linfocitario difuso leve. Tejido conjuntivo perineural con un foco de infiltrado linfocitario neoplásico. 


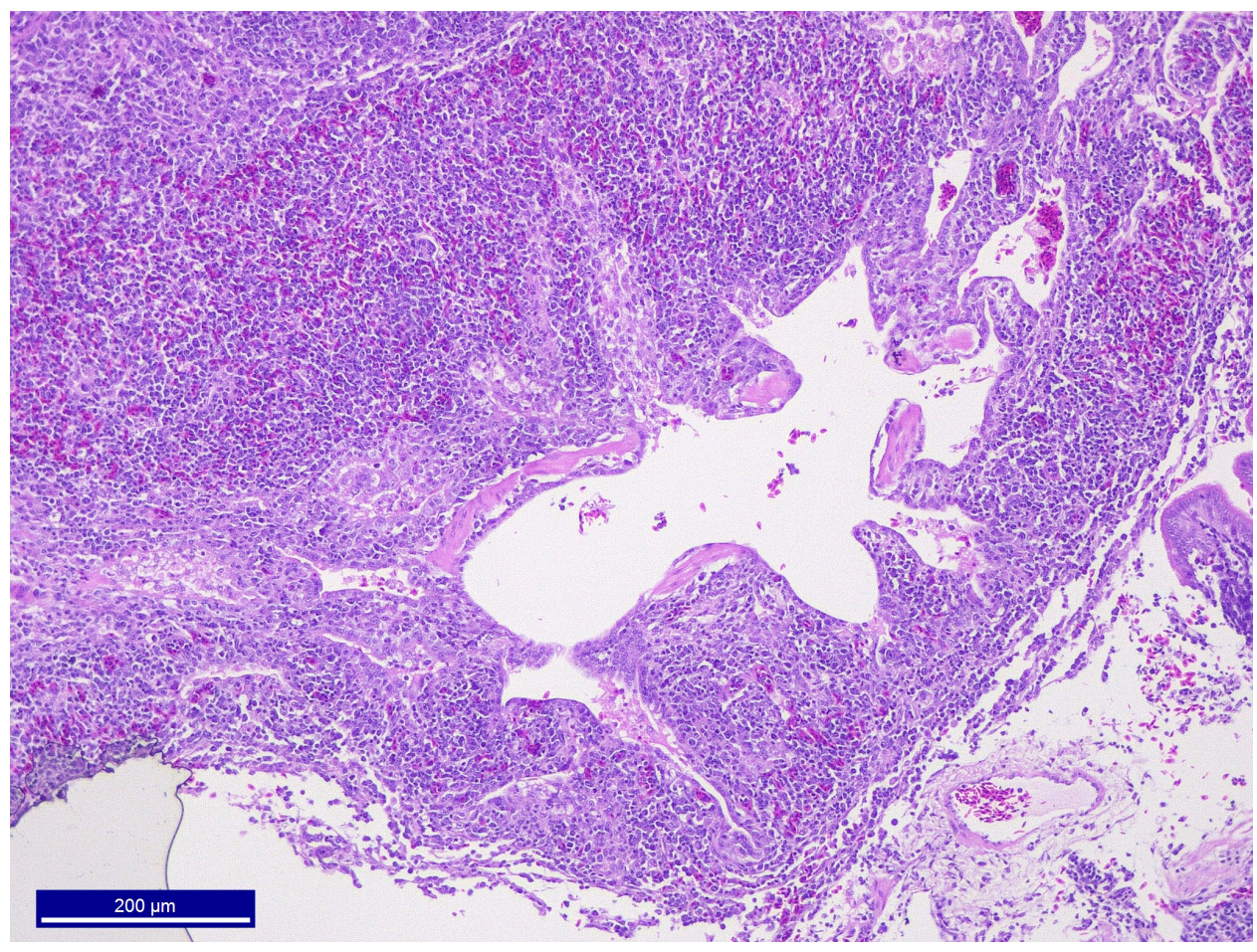

Figura 9. Pulmón. Infiltrado difuso de linfocitos neoplásicos.

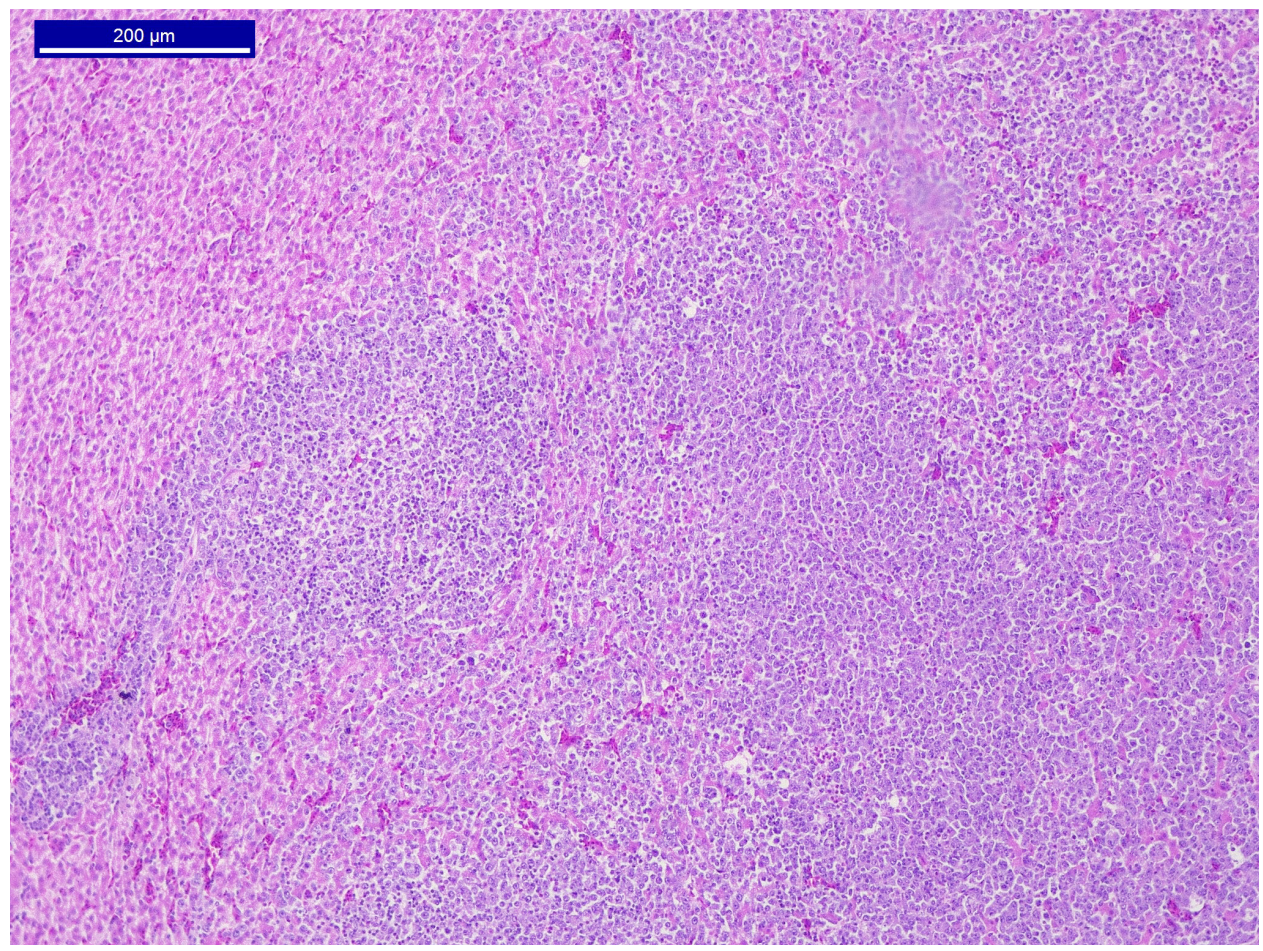

Figura 10. Hígado. Infiltrado difuso de linfocitos neoplásicos. 


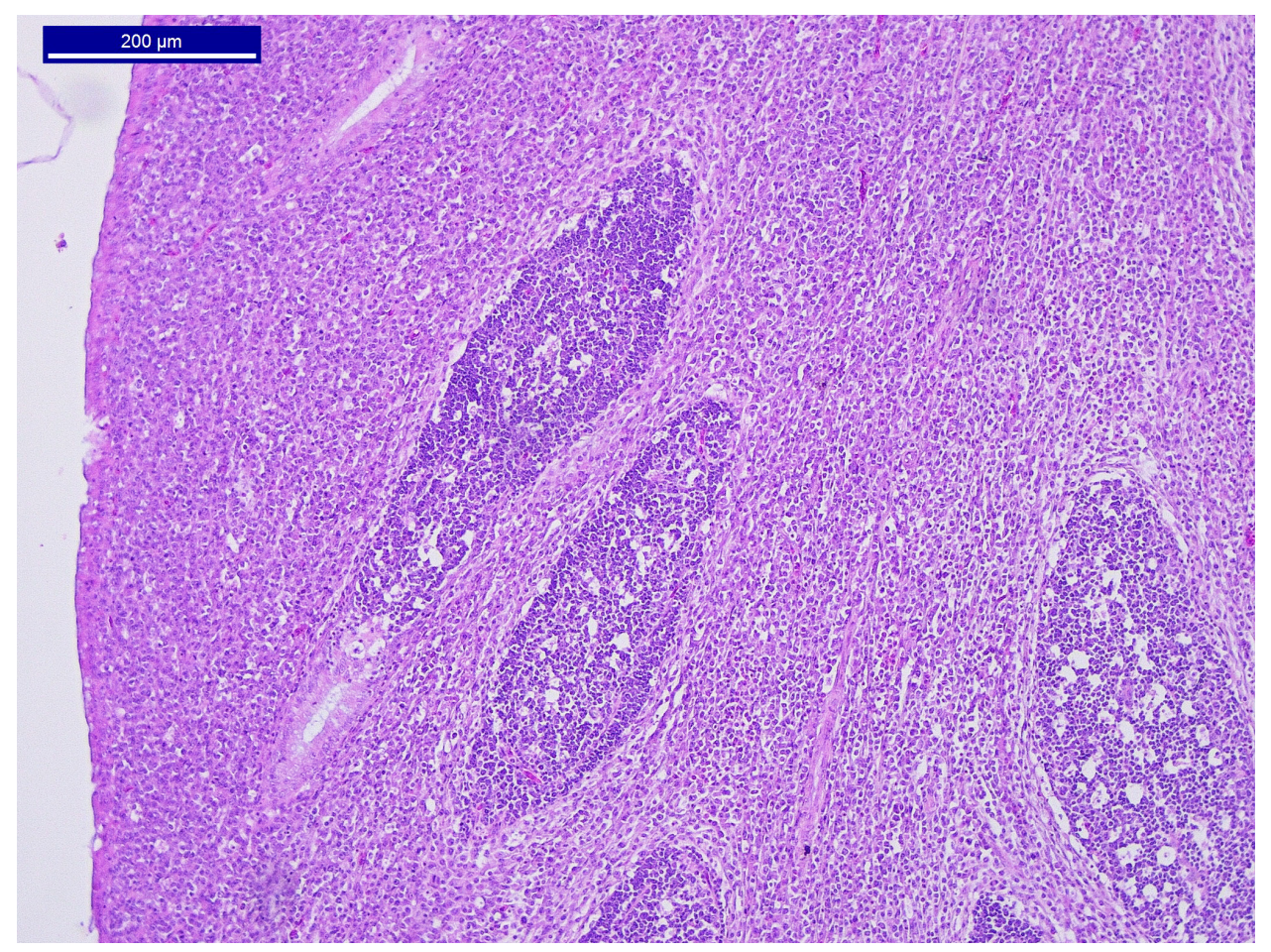

Figura 11. Bolsa de Fabricio. Infiltrado intersticial severo de linfocitos neoplásicos.

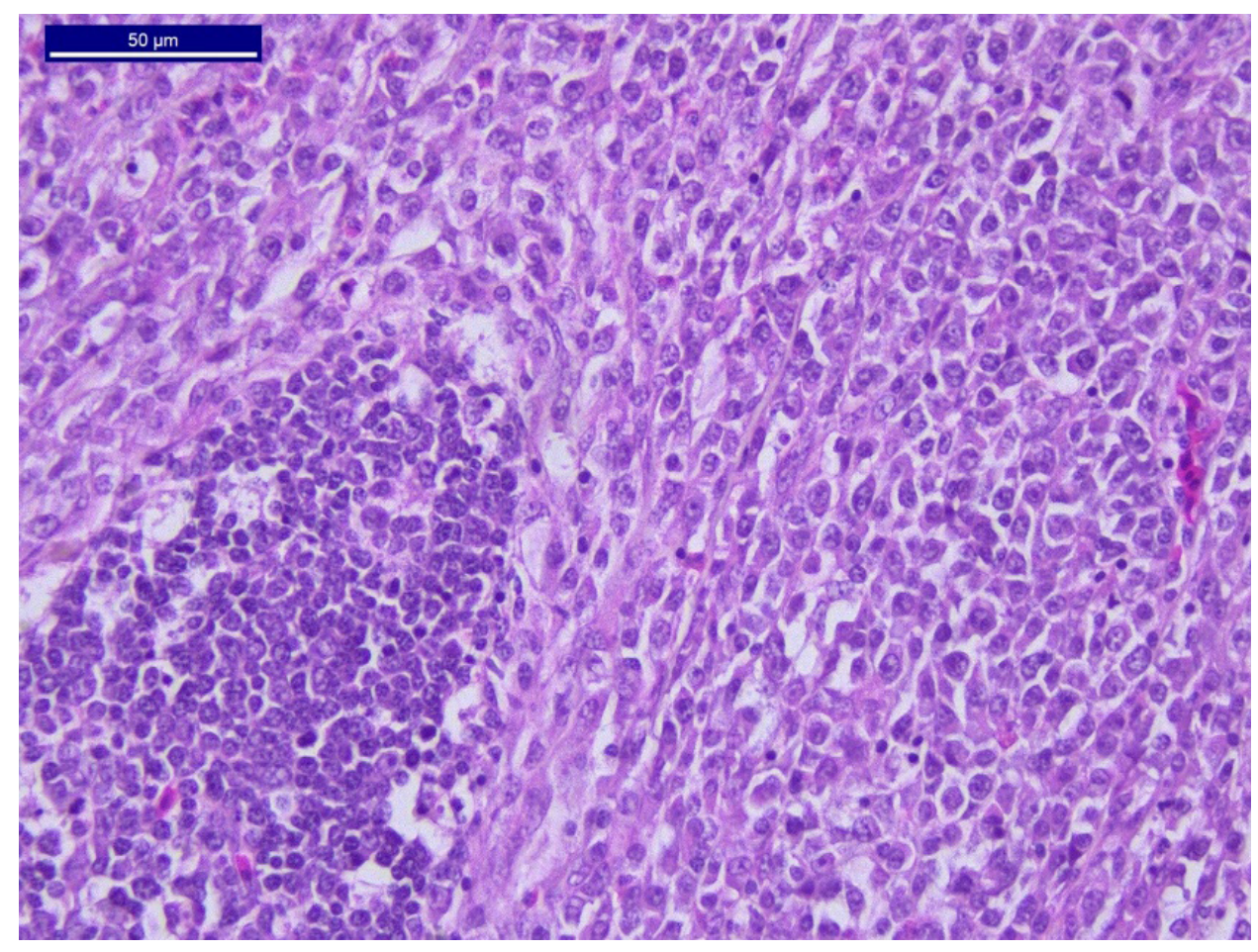

Figura 12. Bolsa de Fabricio. Infiltrado intersticial con linfocitos pleomórficos. Folículo con linfocitos normales. 


\section{Pruebas de laboratorio}

Muestras de tejido perineural, encéfalo, nervio ciático braquial, pulmón, corazón, hígado, duodeno, páncreas, riñón, bazo, ciegos, bolsa de Fabricio y piel procedente de los senos infraorbitarios se fijaron en formol al $10 \%$. Posteriormente, las muestras se incluyeron en parafina, se cortaron $y$, finalmente, se tiñeron con H\&E.

Para determinar la severidad y virulencia del virus infectante, se emplearon los siguientes criterios: poco infiltrado linfocitario disperso en el tejido o de manera perivascular, así como las lesiones vasculares $(+)$, infiltrado linfocitario moderado perivascular y multifocal en tejido $(++)$, y severo infiltrado linfocitario, multifocal o coalescente, conformado en diferentes capas, que produce la pérdida de la arquitectura celular $(+++){ }^{1}$

\section{Discusión y relevancia clínica}

Los hallazgos en la necropsia e histopatología coinciden con lesiones infiltradas de linfocitos pleomórficos (linfomas), células plasmáticas y macrófagos, características de la EM. ${ }^{2}$ Todos los casos clínicos coinciden en la falta de un calendario de vacunación bien establecido y de bioseguridad en el alojamiento que en su mayoría fueron sistemas de producción de traspatio, en piso de tierra y a multiedades, lo que incrementa la posibilidad de contraer Marek.

La EM es neoplásica, la genera un herpesvirus de la familia Herpesviridae, que se distingue por ser linfotrópico y afectar principalmente a los nervios periféricos, ${ }^{3}$ en donde los signos clínicos más frecuentes son paresia progresiva, parálisis de una o más extremidades, cuello penduloso, distención del buche, incoordinación, ceguera, caquexia, anorexia, depresión, deshidratación y diarrea. ${ }^{2}$

Existen dos formas de que la enfermedad se presente: aguda y clásica que se caracteriza por la formación de múltiples tumores en tejidos internos y el engrosamiento de los nervios periféricos, principalmente los braquiales y ciáticos, que paralizan, cuya forma es la espástica progresiva de las alas y los miembros pélvicos. En la inspección ante mortem de los casos clínicos, se identificó esencialmente la parálisis de los miembros pélvicos, zonas aptéricas, lesiones en la región orbitaria y pericloacal, sucia por heces y uratos adheridos a las plumas; se ha reportado que cuando se afectan los nervios intestinales, puede haber impactación, diarrea o pérdida de peso. ${ }^{3}$

Las lesiones macroscópicas observadas en aves infectadas por la EM se han categorizado en cinco tipos: cutánea, visceral, muscular, ocular y neural. Los hallazgos macroscópicos primordiales identificados en las doce aves fueron en el tejido nervioso, donde los plexos lumbosacros, nervios braquiales y ciáticos estaban engrosados en todos los grados de leve a severo, y en estos nervios, se perdieron las estriaciones en la mayoría de los casos.

Se ha reportado que las lesiones neurales son las más fáciles de observar a nivel clínico, pero, se han identificado en el plexo celiaco, mesentérico, craneal, braquial y ciático, a partir de las seis semanas de edad, sitios donde los nervios pierden las estriaciones, cambian de color de perlado a gris amarillento $y$, en ocasiones, están edematizados ${ }^{5}$. Así también, los nervios periféricos braquiales y ciáticos se engrosan de forma unilateral o bilateral. ${ }^{2-3}$ 
Las lesiones características de la EM son infiltrado de linfocitos pleomórficos (linfomas), células plasmáticas y macrófagos. ${ }^{2}$ Algunos de estos traen células tumorales reales que acarrean antígenos para LT en la superficie y antígenos asociados a tumor (MATSA). ${ }^{4}$ Dentro de los tejidos más afectados se encuentran los nervios periféricos, que se afectan de forma proliferativa, inflamatoria o crónica, lo que clasifica a las lesiones en tres tipos: A, B o C, respectivamente. ${ }^{3}$

En esta investigación, se encontró esencialmente la forma $\mathrm{C}$-una forma leve de la $B$, que en aves es asintomática de la $E M-{ }^{2-3} y$, menor frecuencia, la $B$ caracterizada por edema neuronal, proliferación de células de Schwann; así como una ligera a moderada dispersión de pequeños linfocitos y células plasmáticas. La lesión B se observa comúnmente en aves cuando la EM tarda en expresarse. ${ }^{4-5}$

Primordialmente en el sistema nervioso central (SNC), se localizan las lesiones de proliferación de linfocitos, lesiones inflamatorias y de encefalomielitis viral, microgliosis y endoteliosis. Cuando hay parálisis transitoria, es posible que se produzca edema vascular y cúmulos de linfocitos perivasculares. ${ }^{3}$

La EM no es la única enfermedad capaz de inducir la producción de neoplasias, la leucosis aviar (LA), del grupo de leucosis/sarcoma, también tiene la capacidad de inducir la formación de estas lesiones. En esta investigación, la identificación de infiltrados pleomórficos en nervios e hígado, así como la depleción linfocitaria en el bazo y la atrofia de la bolsa de Fabricio sugieren un diagnóstico enfocado a la EM, debido a que se ha reportado que esta enfermedad forma linfomas pleomórficos, afecta a los nervios periféricos y atrofia el tejido linfoide. ${ }^{6}$ Por otro lado, la infección de LA en aves se presenta en la mayoría de los casos con infiltrados linfocitarios homogéneos junto con la ausencia de atrofia de tejido linfoide. ${ }^{7}$

Wen et al. (2018) demostraron que las lesiones neoplásicas en las glándulas del proventrículo de gallinas reproductoras se identificaron con la presencia del antígeno de la EM y LA; aunque, no fue lo mismo para las neoplasias del bazo e hígado, en donde se identificó el antígeno LA y EM, respectivamente. ${ }^{8}$

Debido a la complejidad del diagnóstico de las enfermedades neoplásicas en aves, se ha sugerido tomar en cuenta la historia clínica, el lugar donde se alojan las neoplasias como ojo, nervios, piel y bolsa de Fabricio (identificar si hay atrofia); así como la morfología de las células neoplásicas ${ }^{9}$ con el fin de establecer un diagnóstico basado en la patología.

La enfermedad de Marek adquiere su importancia en la avicultura mexicana, debido a diversos factores, entre los que destacan: la persistencia en aves vacunadas y no vacunadas a través de las descamaciones cutáneas y plumíferas y la susceptibilidad a cepas de campo, que difieren de las cepas vacunales. En este estudio se registró que a seis de los siete casos clínicos se aplicó solo una de las vacunas (ENC, VTA, VA, BI y VEM) sin un programa de salud establecido, por ello las enfermedades virales fueron más frecuentes.

Fuentes-Mascorro et al. (2012) identificaron que el $68 \%$ de las personas dedicadas a los gallos, aplican VTA en periodos de 6 a 12 meses, ${ }^{10}$ vacunan contra EM solo el primer día de vida del pollito, debido a que carecen de información acerca de las vacunas que se requieren y a que la presentación comercial no es accesible para la cantidad de aves que se manejan. 


\section{Financiamiento}

El financiamiento fue cubierto por los propietarios de cada uno de los siete casos clínicos remitidos al Laboratorio del Diagnóstico e Investigación en Enfermedades de las Aves del Departamento de Medicina y Zootecnia de Aves.

\section{Conflictos de interés}

Los autores declaran que no hay conflictos de interés para la publicación de esta investigación.

\section{Contribución de los autores}

NLCA fue el patólogo responsable del diagnóstico, el trabajo fotográfico, la escritura y revisión del manuscrito.

MIAM recopiló el archivo y escribió el manuscrito.

APZV escribió el manuscrito e hizo la revisión bibliográfica.

\section{Referencias}

1. Mete A, Gharpure R, Pitesky ME, Famini D, Sverlow K, Dunn J. Marek's disease in backyard chickens, a study of pathologic findings and viral loads in tumorous and nontumorous birds. Avian diseases. 2016 Dec 1;60(4):826-36. doi: 10.1637/11458-062216-Reg.

2. Hernández $X$, Petrone VM, Téllez Gl. Enfermedad de Marek. Veterinaria México. 2000;31(4):353-67.

3. McFerran JB, McNulty MC. Virus infections of birds: virus infections of vertebrates series. London (UK): Elsevier; 1994.

4. American Association of Avian Pathologists. Avian viral tumors. 3rd ed. lowa (US): Avian Disease Manual; 1989.

5. McPherson MC, Delany ME. Virus and host genomic, molecular, and cellular interactions during Marek's disease pathogenesis and oncogenesis. Poultry Science. 2016;95(2):412-29.

6. Schat KA, Nair V. Marek's diseases. En: Swayne DE. Diseases of poultry. 13th ed. lowa (US): Wiley-Blackwell; 2017. p. 515-51.

7. Nair V, Fadly AM. Leukosis/sarcoma group. En: Swayne DE. Diseases of poultry. 13th ed. lowa (US): Wiley-Blackwell; 2017. p. 551-3.

8. Wen Y, Huang Q, Yang C, Pan L, Wang G, Qi K, Liu H. Characterizing the histopathology of natural co-infection with Marek's disease virus and, subgroup J avian leucosis virus in egg-laying hens. Avian Pathol. 2018 Feb;47(1):83-9.

9. Beyer J, Noël R, Vogel K, Werner O, Plenio C. Studies on the reliability of hard diagnosis of Marek's disease and lymphoid leukosis of chickens on the basis of pathologic-anatomical findings. Arch Exp Veterinarmed. 1980;34:826-46.

10. Fuentes-Mascorro G, Salvador B, García MA. Aves de combate en el traspatio. AICA. 2012;2:313-8. 